\title{
Uso de mapas semânticos no processo de naming - uma abordagem estratégica em um estudo de caso aplicado
}

\author{
Use of semantic maps in the naming process - a \\ strategic approach to a case study applieds
}

\author{
Michel Refatti, Michela Cristiane França Goulart, \\ Mônica Stein, Eugenio Andres Diaz Merino
}

naming; processo

criativo; mapas

semânticos; gestão da informação; gestão de design. naming; criative process; semantic maps; information management; design management.

\begin{abstract}
Naming é o processo de criação e desenvolvimento de nomes. É uma atividade complexa que requer sonoridade, criatividade e pertinência semântica em relação ao produto, ou serviço, em questão. O processo de Naming necessita propor uma solução única e diferenciadora, podendo haver dificuldade em casos em que nomes similares já tenham sido utilizados. Dessa forma, criatividade é um elemento fundamental, bem como o uso de métodos e ferramentas que contribuam para que esse processo ocorra. Nesse sentido, este artigo demonstra a aplicabilidade de mapas semânticos como possibilidade inovadora no processo de naming, em um estudo de caso da marca Buenna. Ao final, são apresentados os resultados dos mapas enquanto ferramentas estratégicas potenciais de Gestão da Informação Aplicada, contribuindo para o âmbito das áreas de Gestão de Design e Publicidade.
\end{abstract}

Naming is the creation process and development of names. It is a complex activity that requires sound, creativity and semantic relevance to the product or service in question. The Naming process requires a unique and differentiated solution may be difficult in cases where similar names have already been used. Thus, creativity is a key element, as well as the use of methods and tools that contribute to this process to occur. In this sense, this paper demonstrates the applicability of semantic maps as innovative ability in the process of naming in a case study of Buenna brand. At the end, the results of the maps as potential Applied Information Management strategic tools, contributing to the scope of the areas of Design Management and Advertising are presented.

\section{Introdução}

Naming é processo de criação de nome de uma marca e está se tornando cada vez mais importante devido à internacionalização das empresas e ao mesmo tempo da dificuldade de criação de um nome criativo, significativo e relevante (BARBOSA, 2011). Esta atividade é uma atividade complexa, pois o nome de um produto requer 
sonoridade, criatividade e pertinência com o produto em questão (MARTINS, 2006). Além disso, necessita ser único e diferenciador, o que dificulta sua criação já que muitos dos nomes já foram utilizados.

Diante desse panorama, o artigo tem como objetivo propor o uso da gestão da informação aplicada a processos metodológicos pertinentes ao design por meio de mapas e painéis semânticos como método de criação de um nome. Mapas semânticos são estruturas de informações representadas graficamente e tem como característica abordar a ideia principal de várias formas e relacioná-la com outras ideias (steIn, 2012). Considera-se, o mapa semântico um tipo de mapa de conhecimento que permite registrar o conhecimento individual e coletivo, possibilitando um léxico comum (costa, 2003).

O artigo justifica-se por contribuir com as áreas de Gestão de Design e publicidade, trazendo a aplicação da Gestão da Informação, por meio do uso de mapas semânticos, no processo de naming.

\section{Procedimentos metodológicos}

A pesquisa é de natureza aplicada com vistas à aplicação de conhecimentos no desenvolvimento de atividades e produtos; e qualitativa quanto à forma de abordagem onde não será requerido o uso de métodos e técnicas estatísticas. É uma pesquisa exploratória quanto aos seus objetivos, que, de acordo com Gil (2010) tem por objetivo proporcionar maior familiaridade com o problema a fim de torná-lo mais claro, explícito ou a construir hipóteses.

Quanto aos procedimentos técnicos, à pesquisa foi dividida em duas etapas distintas, Etapa 1 - da pesquisa bibliográfica e Etapa 2- do estudo de caso. A pesquisa bibliográfica, de acordo com Marconi e Lakatos (2007), envolve a bibliografia publicada relacionada ao tema de estudo e objetiva colocar o pesquisador em contato o estado da arte sobre o assunto. Quanto ao estudo de caso, segundo Gil (2010, p. 58) é um método caracterizado por um "estudo profundo e exaustivo de um ou de poucos objetos, de maneira que permita o seu amplo e detalhado conhecimento".

$\mathrm{Na}$ etapa 1 da pesquisa bibliográfica foi realizada uma revisão teórica em teses, dissertações, livros, periódicos, anais de eventos científicos e materiais disponibilizados na internet. $\mathrm{O}$ embasamento teórico da pesquisa teve como temas principais: Design e Gestão de Design, Gestão da Informação e Naming.

O estudo de caso é um método caracterizado pelo "estudo profundo e exaustivo de um ou de poucos objetos, de maneira que permita o seu amplo e detalhado conhecimento" (GIL, 1991, P. 58). Dessa forma, os resultados são válidos só para o caso que se estuda, sem a possibilidade de generalização dos resultados atingidos. No entanto, de acordo com Triviños (1992, p.111) o valor do estudo de caso está em "fornecer o conhecimento aprofundado de uma realidade 
delimitada que os resultados atingidos podem permitir e formular hipóteses para o encaminhamento de outras pesquisas".

A complexidade de um estudo de caso, segundo Triviños (1992) é determinada pela natureza e abrangência da unidade de estudo e pelos suportes teóricos que acabam por orientar o pesquisador durante sua investigação. Na etapa 2 do estudo de caso, foram utilizadas entrevistas não estruturadas aplicadas junto ao grupo de designers e publicitários bem como utilizados mapas conceituais, cognitivos e mentais.

\section{Fundamentação teórica}

\subsection{Naming}

De acordo com Neumeier (2008, p.2), marca é "a percepção íntima, o sentimento visceral de uma pessoa em relação a um produto, serviço ou empresa”. Essa conceitação diz respeito às escolhas do consumidor que passam a ser simbólicas e onde as marcas recebem maior importância no mercado. A marca é considerada um ativo intangível, que segundo Kaplan e Norton (2004), representam mais de $75 \%$ do valor das empresas.

Uma marca de acordo com Kotler (2000) pode ser um nome, termo, símbolo, desenho ou uma combinação desses elementos a fim identificar os bens ou serviços de uma empresa ou grupo de empresas para diferenciá-los dos da concorrência. Segundo Keller (2006, p. 66) "marcas fortes possuem maior fidelidade e menor vulnerabilidade às ações da concorrência”. Esta realidade faz com que a criação de marcas seja um diferencial competitivo para as empresas.

O nome pode ser o ativo mais valioso de uma marca quanto a sua diferenciação e aceitação (NEUMEIER, 2008). O processo de criação de nome de uma marca é chamando de naming e é realizado por agências de publicidade e comunicação, marketing e escritórios de design com o objetivo de desenvolver nomes criativos e significativos. É uma atividade interdisciplinar que depende de conhecimentos específicos, como linguística, marketing, design e direito (RODRIGUES, 2011; MARTINS, 1999). Nome é uma palavra usada para dar sentido e diferenciar as coisas, lugares, animais e pessoa. A palavra tem o poder de comunicar e transmitir sentimentos, criando percepções e associações.

Segundo Ries (2009, p. 83) "a decisão mais importante de marketing que você pode tomar é escolher o nome do produto”. A criação de nomes de marca é uma atividade complexa tendo em vista que muitos dos nomes já foram utilizados e estes necessitam ter sonoridade, criatividade e pertinência com o produto em questão. Além disso, necessitam ser únicos e diferenciadores. Criatividade e 
imaginação são elementos fundamentais na criação de um nome, bem como o uso de métodos que contribuam ao processo de Naming.

Segundo Kotler as qualidades desejáveis para um nome são:

Deve dizer algo a respeito dos benefícios do produto. Deve sugerir as qualidades do produto, como uma ação ou cor. Deve ser fácil de pronunciar, de reconhecer e de lembrar, nomes curtos ajudam. Deve ser inconfundível. Não deve apresentar significados negativos em outros países e línguas (коTLER, 2000, Р. 435).

De acordo com Keller:

Tudo pode ser usado para formar um nome (pessoas, lugares, animais, objetos inanimados). E, uma vez que esses elementos já existem na memória em forma verbal e visual, a aprendizagem necessária é menor e a formação de vínculos com o nome do objeto ou do produto é mais fácil, o que aumenta a memorabilidade. (KELLER. 2006, P. 97).

Mudar a grafia das palavras é um recurso muito útil para aumentar a lembrança das palavras. Shin (2009) diz que o consumidor se lembra com muito mais facilidade de grafias em comuns, como o uso de "h", "y" e a duplicação de vogais ou consoantes. De acordo com Keller (2006, p. 96) "Em geral, acredita-se que a lembrança de marca seja facilitada na mesma proporção em que os nomes escolhidos forem simples e fáceis de pronunciar e escrever".

Segundo o próprio Keller:

Para melhorar a pronúncia e a lembrança, muitos profissionais de marketing buscam uma cadência desejável e um som agradável para seus nomes de marca. Por exemplo, nomes de marca podem usar aliteração (repetição de consoantes, como em Coleco), assonância (repetição de som de vogais, como em Ramada Inn), consonância (repetição de consoantes com uma mudança na vogal interveniente, como Hamburger Helper) ou ritmo (repetição padrão de sílabas tônicas, como Better Business Bureau) (KELlER, 2006, P. 97).

Todos esses aspectos para a criação do nome foram sintetizados por Neumeier (2008, p.85) em sete critérios da escolha de um bom nome, sendo eles:

1. Distinguibilidade: refere-se a capacidade de distinguir a marca;

2. Brevidade: refere-se ao quanto o nome é curto para ser facilmente lembrado;

3. Conveniência: refere-se ao quanto o nome está ajustado ao propósito comercial da empresa;

4. Grafia e pronúncia fáceis: refere-se à facilidade de escrita e pronúncia; 
5. Agradabilidade: refere-se ao quanto são agradáveis ao público-alvo;

6. Extensibilidade: refere-se à possibilidade de adequação a diferentes finalidades criativas e

7. Possibilidade de proteção: refere-se aos aspectos legais do uso e registro do nome.

Apreende-se que não existe um método único no processo de criação de nomes de marcas. Todos os passos ou métodos sugeridos por autores que abordam o processo de naming não desconsideram o fato que dar nomes é um processo rigoroso e exaustivo e que técnicas são necessárias a fim de verificar a eficácia de um nome e garantir que suas conotações sejam positivas no mercado a ser atendido (WHEELER, 2012).

No processo de criação e construção de nomes o design desempenha um papel essencial e que de acordo com Moira Cullen, diretora sênior em design global da Hershey, o design diferencia e incorpora os elementos intangíveis, como emoção, o contexto e a essência, que mais importam aos consumidores (WHEELER, 2012).

\subsection{O Design e a Gestão de Design no naming}

O papel estratégico da criação da personalidade para as empresas através do naming, se relacionada ao design em seu processo criativo. Design, de acordo com ICSID (2014), é uma atividade criativa cuja finalidade é estabelecer as qualidades multifacetadas de objetos, processos, serviços e seus sistemas, compreendendo todo seu ciclo de vida. Este estabelecimento de qualidades inclui-se também o processo de naming, no qual o designer atribui qualidades que são comunicadas pelo nome e estabelecem conexões com o público-alvo.

Kotler corrobora quando afirma que o domínio do design não se limita aos produtos, mas inclui também sistemas que determinam a identidade pública da empresa design gráfico, embalagens, publicidade, arquitetura, decoração de interiores das fábricas e dos pontos de venda (INTRODUÇÃO... 2014).

Todos os negócios dos quais se incluem o design diz respeito a Gestão de Design; abrangendo os processos, as decisões de negócios e estratégias que permitem inovar e desenvolver produtos eficazmente bem como serviços, comunicações, ambientes e marcas que melhoram a qualidade de vida e proporcionam o sucesso organizacional. A Gestão de Design visa, dentre outros objetivos oferecer vantagem competitiva pelos fatores sociais, culturais e ambientais (DMI, 2014).

Ao se nomear um processo, um tipo de serviço ou uma nova característica de serviços, está se criando um valioso ativo que, de acordo com Wheeler (2012) tem o potencial de ser uma campanha publicitária. Sendo assim, de acordo com a autora, o processo de naming requer uma abordagem criativa, estudada e estratégica. 
A Gestão de Design distingue-se de outros processos gerenciais pela identificação e a comunicação das possibilidades pelos quais o design pode contribuir ao valor estratégico da empresa, ou seja, as maneiras das quais o design pode ajudar a empresa a construir a sua estratégia (MARTINS E MERINO, 2011).

A estratégia de marca proporciona uma ideia que unifica comportamentos, ações e comunicações das empresas e precisa ser entendida por todos os stakeholders em todos os pontos de contatos da marca. Os pontos de contato da marca, conforme observado na Figura 1, configuram-se em possibilidades de memorização e fidelização do cliente.

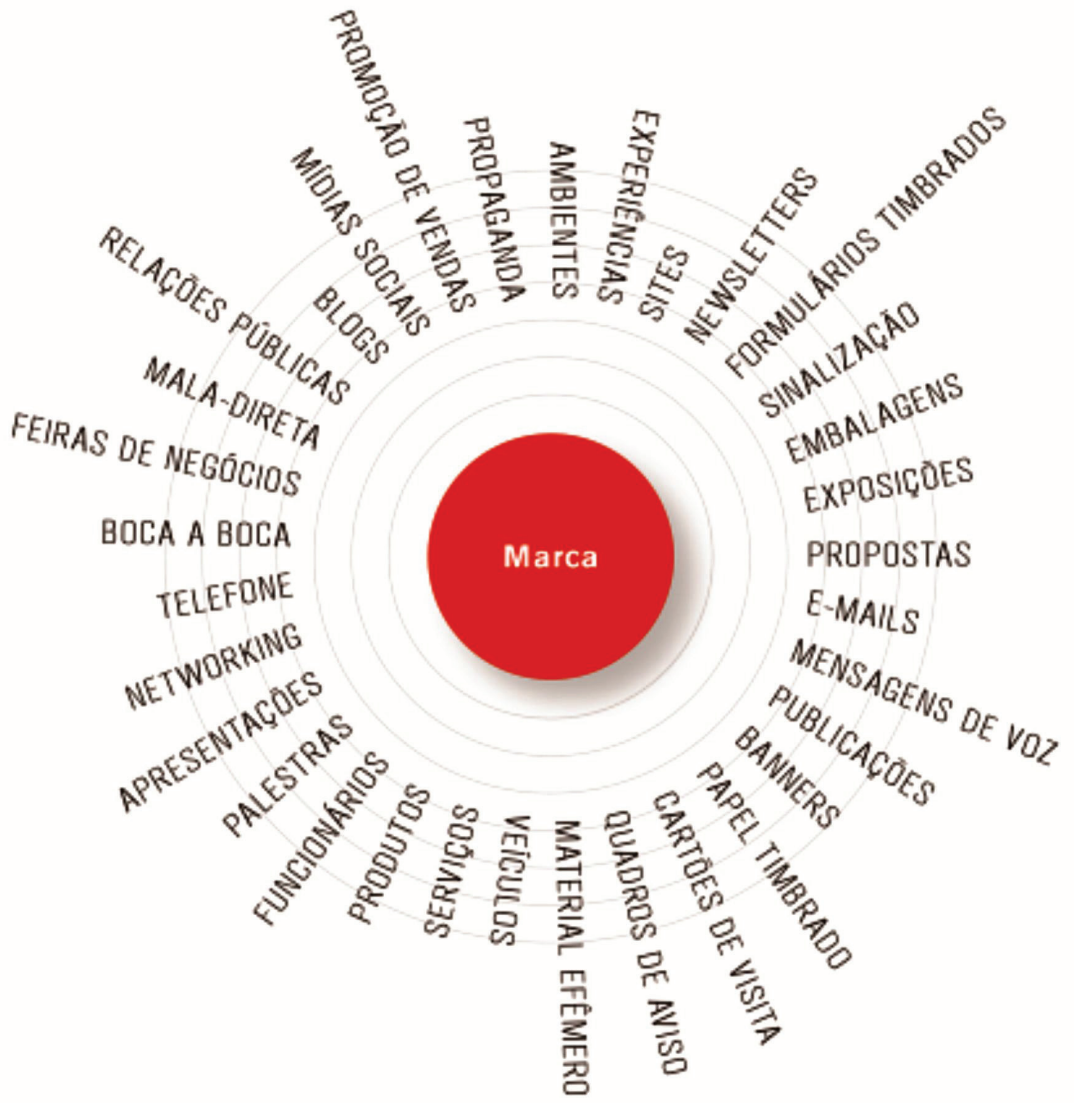

Figura 1 Pontos de contato com a marca. (Fonte: Wheeler, 2012, p.13)

Sendo assim, para uma comunicação eficaz faz-se necessário o suporte de áreas como gestão da informação.

\subsection{Gestão da Informação}

A informação é considerada um dos principais insumos das organizações, pois quando gerenciadas eficazmente é fator de crescimento de lucros, de redução de custos operacionais, de 
otimização do processo decisório, de solução de problemas e de eliminação de barreiras comunicacionais, entre outros fatores que melhoram o desempenho organizacional (BEAL, 2012). De acordo com a autora, com o aumento da complexidade e do dinamismo do ambiente externo as organizações passaram a depender de mecanismos para lidar com as informações a fim de reduzir as incertezas nas tomadas de decisão e melhorar o relacionamento com parceiros, clientes, fornecedores e agentes reguladores.

Neste contexto insere-se a Gestão da Informação que tem por objetivo apoiar a gestão das empresas por meio de processos que tornem as informações mais acessíveis e eficazes de modo que o conhecimento seja propiciado. Ainda, a gestão da informação dá subsídios às empresas para o processo de tomada de decisão e desempenha um papel estratégico (VALENTIM, 2010).

\subsection{Gestão da Informação sob a ótica do Design - Uso de mapas} semânticos

Segundo Stein (2012), mapas semânticos são estruturas de informações organizadas graficamente, onde a informação é interligada de acordo com o significado das palavras. Tem como característica identificar a ideia principal e relacioná-las com as demais ideias, contemplando detalhes complementares, como características, temas, subtemas, etc.

\subsubsection{Mapas Mentais}

Os mapas mentais são comumente usados em processos de gestão da informação em processos de gestão estratégica nas empresas. Viabilizam interligações simples entre palavras/objeto através de seus significados por meio de linhas/ramificações. Devido a sua facilidade de uso, esse modelo também foi adotado pela comunidade digital, para realização de mapeamento e planejamento de sites e blogs, desenvolvimento de softwares, acompanhamento de bugs, planejamento de layouts e funcionalidades de programas.

\subsubsection{Mapas Conceituais}

O mapa conceitual é uma ferramenta para organizar e graficamente relações significativas entre os conceitos de um determinado assunto/ objeto de estudo/projeto. Os conceitos aparecem em caixas e a relação entre eles é indicada por uma linha que os une. Essa linha deve conter uma frase (proposição), muitas vezes um verbo conjugado, de acordo com o sentido que se quer dar. Para Amaral e Quevedo (2013) os 
mapas conceituais podem transmitir informações, com a vantagem de proporcionar aos leitores a elaboração mais rápida de relações entre os conceitos, que dispostos graficamente, facilitando a construção de inferências.

\subsubsection{Mapas Cognitivos}

A cognição alcança todas as formas do conhecimento, como percepção, raciocínio e julgamento (GUIMARÃES, 2007). Os mapas cognitivos apresentam graficamente conjuntos de representações discursivas feitas por um sujeito (o ator) com vistas a um objeto (o problema), em contextos de interações particular, segundo Cossete e Audet (1992). Essa representação gráfica é o resultado da interpretação mental que o analista (facilitador) faz a partir da representação discursiva feita pelo sujeito (ator) sobre um problema. Os mapas cognitivos podem ser usados como produtos (mantendo estáveis) ou como ferramentas (com caráter dinâmico e passível de modificação) e podem ser de (1) identidade (designam as chaves físicas do problema: atores, eventos e processos), (2) de categorização (criam escalas e convenções que oferecem informações sobre o relacionamento entre as entidades do problema), e (3) causais ou de argumentação (com vias alternativas para passar de uma posição a outra no mapa - as ligações potenciais entre a entidade de importância para a organização).

\section{ESTUDO DE CASO: Naming}

\subsection{O Problema}

O estudo de caso trata da criação do nome para um grupo de publicitários e designers que trabalham como freelancers em projetos para agências de publicidade, agências digitais e clientes finais. $\mathrm{O}$ grupo tem como objetivo, além de complementar a renda, realizar trabalhos criativos e de qualidade, o que se torna difícil dentro das agências, devido às exigências de empregadores quanto a tempo e dos clientes. O estudo abrangeu a aplicação de uso dos mapas semânticos no processo de naming.

\subsection{O método}

O estudo de caso usa como base um processo metodológico pertinente ao design que ocorre, geralmente, em três etapas (aqui apresentado de forma resumida): identificação das necessidades, criação, e apresentação dos resultados. Como ferramentas de apoio, nas três 
10 método Gia

(Gestão da Informação

Aplicada) é um

sistema hierárquico

de aplicação de mapas

semânticos a processos

metodológicos

pertinentes ao

design, para solução

de problemas,

desenvolvido pela

professora Dra. Mônica

Stein, e aplicado em

diversas consultorias

empresarias. etapas foram utilizados o mapa cognitivo, mapa conceitual, painel semântico e mapa mental, seguindo uma hierarquia sugerida nas aulas da professora Dra. Mônica Stein, pertinentes ao seu método intitulado Método GIA (Gestão da Informação Aplicada) ${ }^{1}$.

\subsection{Identificação das necessidades: ETAPA 1}

$\mathrm{Na}$ entrevista informal com o grupo para identificação das necessidades foi utilizado um mapa cognitivo para identificar quais estavam relacionadas com a essência do grupo, objetivos, personalidade, quem eram e o que os diferenciava. O grupo ficou livre para comentar, e durante a entrevista o facilitador construiu um mapa cognitivo com as frases chaves, conforme pode ser observado na Figura 2. elementos primários de avaliação foram estabelecidas as palavras: grupo criativo, design e publicidade.

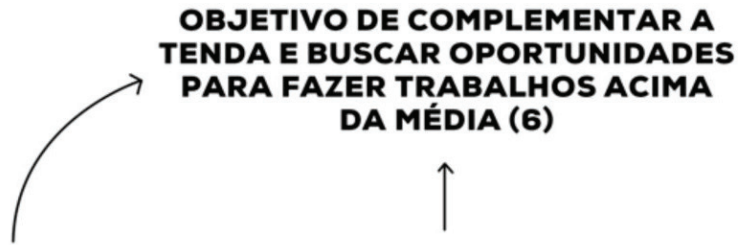

OS DIFERENCIAIS SÃO OS CONTATOS, $O$ COMPROMETIMENTO E PAIXÃO PELO QUE FAZ (5) OTOG E COISAS DA VIDA (4)

PERSONALIDADE AMIGÁVEL, CRIATIVA E DINÂMICA (3)

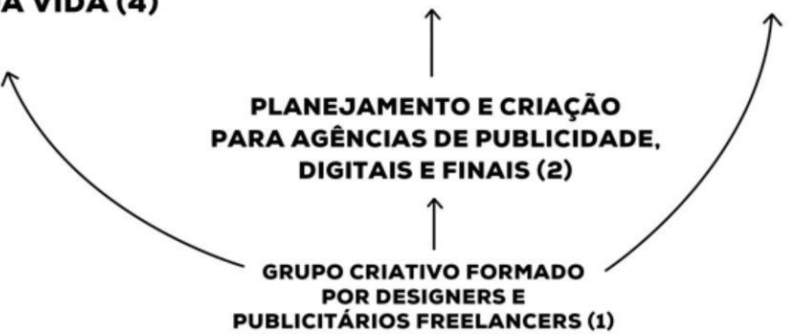

PUBLICITÁRIOS FREELANCERS (1)

ELEMENTOS PRIMÁRIOS DE AVALIAÇÃO GRUPO CRIATIVO DESIGN PUBLICIDADE

Figura 2 Mapa cognitivo. (Fonte: Autoria própria, 2013)

Como elementos primários de avaliação foram estabelecidas as palavras: grupo criativo, design e publicidade.

Durante a conversa com o grupo foi possível estabelecer as relações que orientaram a construção do briefing e das próximas etapas do estudo. Este foi organizado em um mapa conceitual - figura 3. Além das informações obtidas pelo mapa cognitivo foram somadas as palavras relacionadas ao trabalho do grupo em sua estruturação, conforme se pode observar a seguir: 


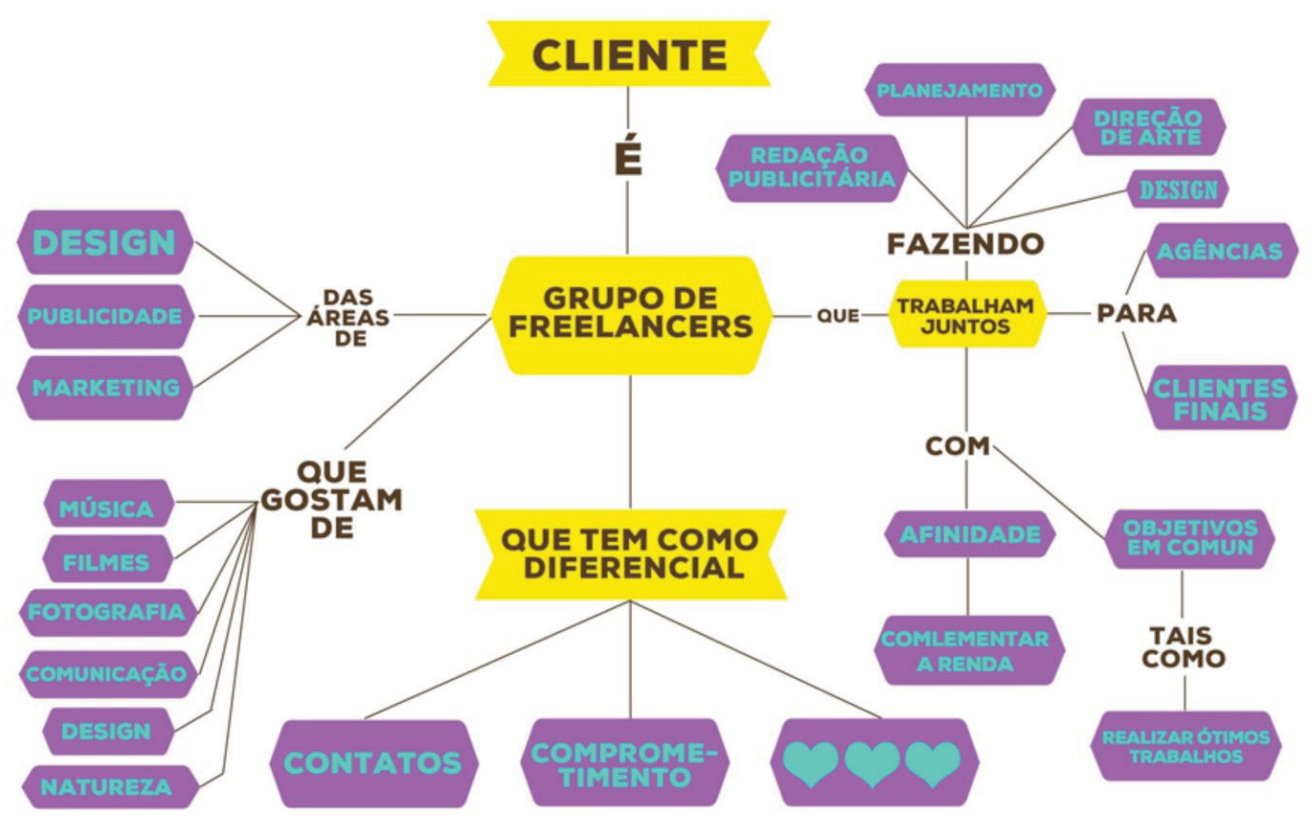

Figura 3 Mapa conceitual do Briefing. (Fonte: Autoria própria, 2013)

\subsection{Criação de Soluções: ETAPA 2 - CRIAÇÃO}

Após a etapa de identificação das necessidades pela análise dos mapas (cognitivo e conceitual), foi realizada uma busca de imagens que representassem os objetivos do grupo. As imagens de tipografias com formatos orgânicos transmitiam valores como a afinidade, o entrosamento e a rede de contatos do grupo. As imagens formaram o painel semântico que foi apresentado e aprovado pelo grupo.

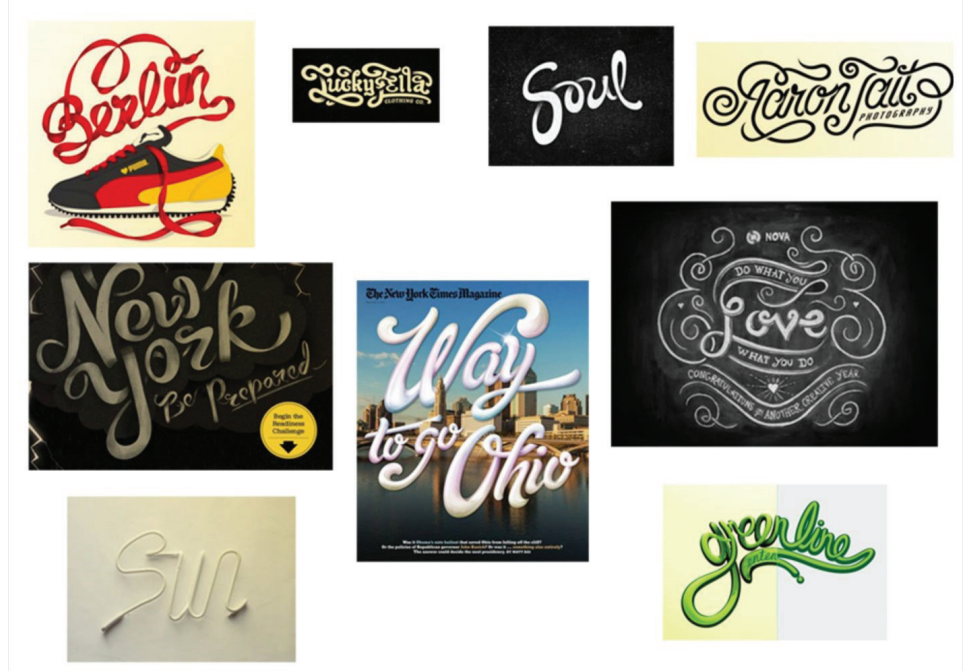

Figura 4 Painel semântico. (Fonte: Autoria própria, 2013) 
Com a ajuda do painel semântico foi criado o mapa mental com ideias de nomes. O mapa teve como desdobramento da ideia central as palavras: arte, grupos, laboratório, nomes relacionados à música e animais ou mascotes onde foram listados nomes desses grupos, conforme pode ser observado na Figura 5.

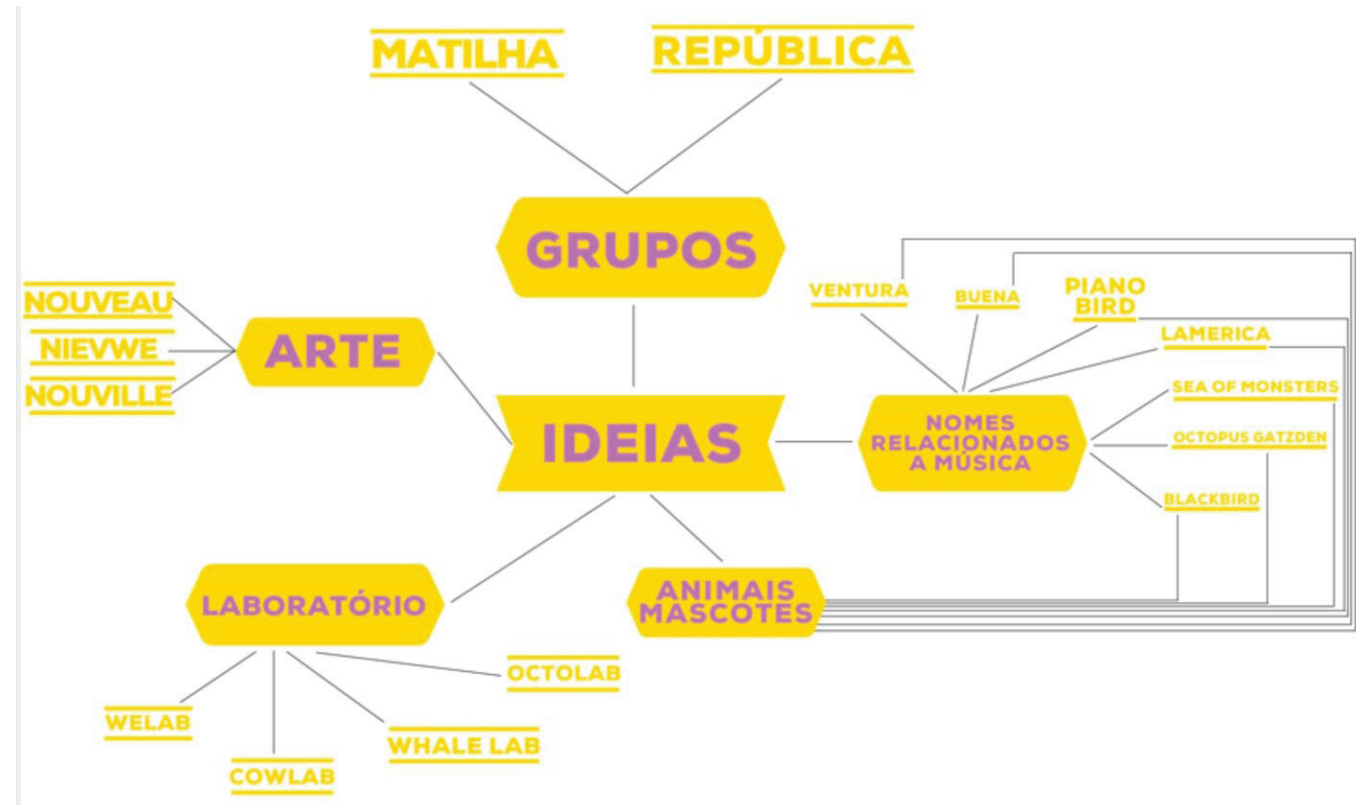

Figura 5 Mapa mental com ideias de nomes. (Fonte: Autoria própria, 2013)

\subsection{Apresentação dos resultados: ETAPA 3}

Dos nomes listados no mapa mental (Figura 5) o que mais se enquadrou com a essência do grupo foi o "Buenna". O nome Buenna remete a alto astral, qualidade, carisma e a saudação de "Bom dia".

Para apresentar a solução, optou-se pelo mapa conceitual que, por sua estruturação com palavras de ligação, permite a fácil compreensão do que fora mostrado. Neste mapa (Figura 6) foi colocado o que o nome escolhido remetia.

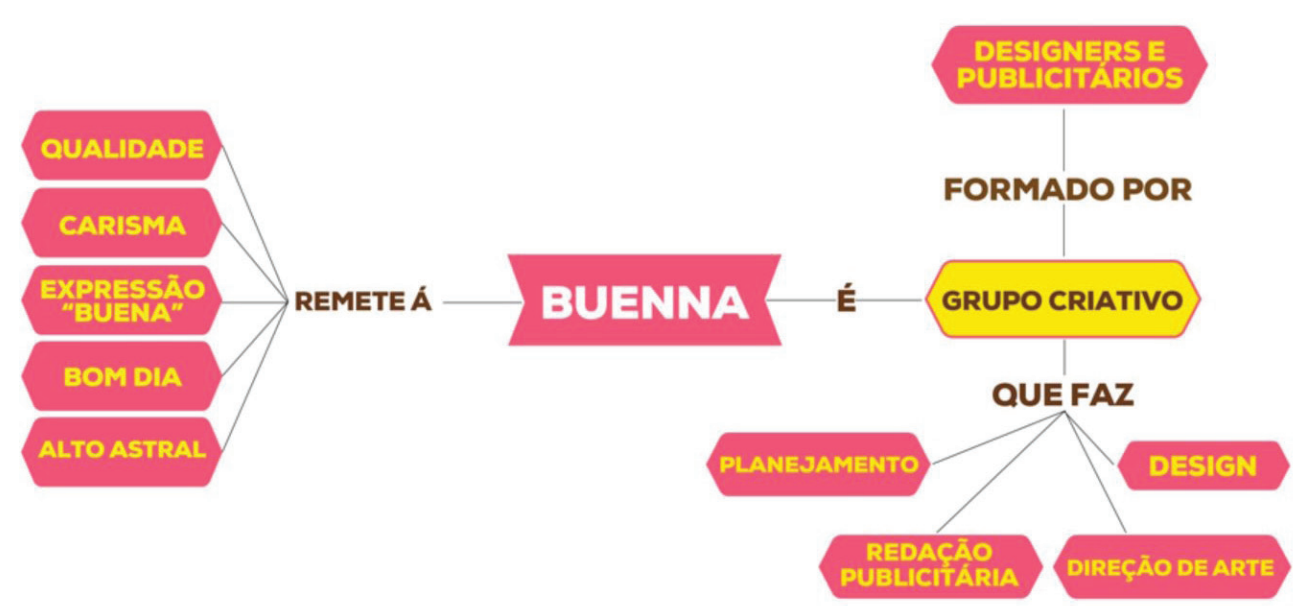

Figura 6 Mapa conceitual com o nome escolhido. (Fonte: Autoria própria, 2013) 


\section{Discussão dos resultados do processo - Uso dos mapas}

Na etapa 1, a execução do levantamento das necessidades do grupo através do mapa cognitivo mostrou-se interessante devido ao ordenamento das frases-chaves e concatenação de ideias. Da mesma maneira, o uso do mapa conceitual nessa etapa demonstrou de maneira clara o briefing resultante da entrevista.

$\mathrm{Na}$ etapa 2 foi realizado um painel semântico e um mapa mental com ideias de nomes. Embora o painel semântico tenha sido gerado antes do mapa mental, foi percebido que o uso das imagens poderia ter sido mais bem aproveitado se fosse gerado de acordo com as categorias de palavras do mapa mental - procedimento este a ser inserido e/ou modificado em projetos futuros de naming.

Na etapa 3, de apresentação do nome escolhido, o uso do mapa conceitual permitiu que fosse compreendido o motivo da escolha em função do que este remetia.

Com base na realização deste estudo de caso, e a partir da análise de seu andamento e resultados, sugere-se o processo de utilização das seguintes ferramentas, conforme suas potencialidades de uso, nas respectivas etapas, conforme o Quadro 1:

Quadro 1 Etapas de processo do processo de naming e ferramentas. (Fonte: Autoria própria (2014))

\begin{tabular}{|l|l|l|}
\hline Etapas & Ferramentas & Potencialidades do uso \\
\hline $\begin{array}{l}\text { Etapa I: } \\
\text { Identificação das } \\
\text { necessidades }\end{array}$ & 1. Mapa cognitivo & $\begin{array}{l}\text { Ordenamento das frases-chaves } \\
\text { e concatenação de ideias. }\end{array}$ \\
\cline { 2 - 3 } & 2. Mapa conceitual & $\begin{array}{l}\text { Apresentação clara e geral } \\
\text { do contexto. }\end{array}$ \\
\hline $\begin{array}{l}\text { Etapa II: criação de } \\
\text { soluçoes }\end{array}$ & 3. Brainstorming & $\begin{array}{l}\text { Liberdade de criação na geração } \\
\text { de ideias. }\end{array}$ \\
\cline { 2 - 3 } & 4. Mapa mental & Categorização de ideias. \\
\cline { 2 - 3 } & 5. Painel semântico & $\begin{array}{l}\text { Transmissão de valores } \\
\text { e emoções. }\end{array}$ \\
\hline $\begin{array}{l}\text { Etapa III: } \\
\text { apresentação dos } \\
\text { resultados }\end{array}$ & 6. Mapa conceitual & Facilidade de compreensão. \\
\hline
\end{tabular}

Destaca-se que essas etapas sugeridas referem-se ao processo de criação do "nome". Porém, é fato a necessidade de uma busca formal e informal para saber da viabilidade do nome, no Instituto Nacional da Propriedade Industrial (INPI) e Registro.br - órgão responsável pelo registro de nomes de domínios, da administração e da publicação do DNS (Sistema de Nome de Domínios) para o domínio “.br”, além dos serviços de distribuição e manutenção de endereços Internet. 


\section{Conclusões}

O artigo apresentou um estudo de caso de naming com uma análise do processo de criação em função do uso de algumas ferramentas da gestão da informação - mapas semânticos - que podem ser utilizados no mesmo, para apontar suas potencialidades. Como resultado, formulou uma tabela com a sugestão destas ferramentas nas respectivas etapas de um processo metodológico de design, contribuindo não somente com esta área, mas com outras diretamente relacionadas, como a publicidade.

\section{Referências}

AMARAL, M. A. QUeVEdo, S. R. P. (2013). Modelagem em um ambiente virtual de aprendizagem inclusivo: uso de mapas conceituais. Revista Brasileira de Design da Informação. Brazilian Journal of Information Design. São Paulo, v. 10, n. 2:137 - 156 .

BARbosa, E. R. (2011). Processo que faz o produto ser identificado no mundo inteiro. Cienc. Cult. [online], v.63, n.3: 64-65. ISSN 0009-6725.

BEAL, A. (2012).Gestão Estratégica da Informação: Como transformação a informação e a tecnologia da informação em fatores de crescimento e de alto desempenho nas organizações. São Paulo: Atlas,135 p.

CosTA, M.D. (2003). Procedimentos para aplicação de mapas semânticos como estratégia para criação do conhecimento organizacional. 197p. Tese. (Doutorado em Engenharia de Produção) - Programa de pós-graduação em Engenharia de Produção, UFSC, Florianópolis.

DESign MANAGEMENT institute (DMI) (BOSTON). (2014). What is design management? Disponível em: <https://www.dmi.org/dmi/html/aboutdmi/ design_management.htm>. Acesso em: 21 mar. 2014.

GIL, A. C. (2010). Como elaborar projetos de pesquisa. São Paulo: Atlas.

guimarÃes, F. M. (2007). Aplicação do mapeamento cognitivo como apoio à implementação de estratégias empresariais: o caso de uma organização hospitalar. 181 p. Dissertação de mestrado em Administração e Negócios, da Faculdade de Administração, Contabilidade e Economia- Universidade Católica do Rio Grande do Sul.

INTERNATIONAL COUNCIL OF SOCIETIES OF INDUSTRIAL DESIGN (ICSID) (CANADA). (2014). Definition of Design. Disponível em: <http://www.icsid.org/about/ about/articles31.htm>. Acesso em: 21 mar. 2014.

INTRODUÇÃo AO DESIGN: CONCEITOS DE DESIGN. (2014). Disponível em: <http:// www.lsc.ufsc.br/ edla/design/conceitos.htm>. Acesso em: 12 mar. 2014.

KAPLAN, R. S.; NORTON, D. P. (2004). Mapas estratégicos: Convertendo ativos intangíveis em resultados tangíveis. 7. ed. Rio de Janeiro: Campus Elsevier, $508 \mathrm{p}$.

Keller, K. L. (2006). Gestão estratégica de marcas. São Paulo: Pearson Prentice Hall.

Kotler, P. (2000). Administração de marketing: a edição do novo milênio. São Paulo: Prentice Hall. 
KOTLER, P. \& ARMSTRONG, G. (2000). Introdução ao marketing. Rio de Janeiro: LTC. MARCONI, M. DE A.; LAKATOS, E. M. (2007). Fundamentos de metodologia científica. 6.ed. São Paulo: Atlas, p. 261-265.

MARTINS, J. R. (2006). Branding: um manual para você criar, gerenciar e avaliar marcas. São Paulo: Ed. Negócio.

MARTINS, R. F. DE F.; MERINO, E. A. D. (2011). A gestão de design como estratégia organizacional. Londrina, PR: Eduel, 222 p.

neumeier, M. (2008). The Brand Gap. O abismo da marca. Porto Alegre: Bookman. RIES, AL \& TROUT, JACK. (2009). Posicionamento: a Batalha por sua Mente. São Paulo: M. Books do Brasil.

RODRIGUES, DELANO. 2011. Naming: o nome da marca. Rio de Janeiro: 2AB.

SHIN, D. (2009). Towards an understanding of the consumer acceptance of mobile wallet. Computers in Human Behavior, v.25, n.6: 1343-1354.

Stein, M. (2012). Mapas semânticos. 27-28 de jul de 2012. Notas de Aula. Aula ministrada no Curso de Especialização em Gestão de Design da Universidade Federal de Santa Catarina.

TRIVIÑos, A. N. S. (1992). Introdução à pesquisa em ciências sociais. São Paulo: Atlas.

valentim, M. (2010). Gestão, mediação e uso da informação. São Paulo: cultura acadêmica.

WHEELER, A. (2012). Design de identidade da marca: Guia essencial para toda a equipe de Gestão de marcas. 3. ed. Porto Alegre: Bookman. 319 p.

\section{Sobre os autores}

\section{Michel Refatti}

$<$ michel.rftt@gmail.com>

Especialista em Design Estratégico, Universidade Federal de Santa Catarina. Formado em Comunicação Contemporânea pela Perestroika Porto Alegre, publicitário pela UFMT, pós-graduado em design estratégico pela UFSC e desistente de Marketing em Mídias Digitais pela Estácio-SC.

\section{Michela Cristiane França Goulart}

$<$ michela.designer@gmail.com >

Mestranda em Gestão de Design e Especialista em Design Estratégico pelo Programa de Pós Graduação em Design da Universidade Federal de Santa Catarina.

\section{Mônica Stein}

<monica.stein@ufsc.br>

Graduada em Arquitetura e Urbanismo pela Universidade Federal de Santa Catarina (1994), é Mestre (1997) e Doutora (2003) em Gestão do Design e do Produto pela mesma universidade - UFSC. Estudou também no MIT (Massachusetts Institute of Techonlogy) em doutorado sanduíche em 2001, e também na Harvard University 
em 2007. Atualmente é professora com dedicação exclusiva na UFSC, no curso de Design. Desde 2007, é Consultora Internacional em projetos estratégicos pelo estado de Massachusetts/EUA, atuando em planejamento, desenvolvimento e implementação de ações estratégicas para os mais diversos fins. Criou, em abril de 2011, o grupo de pesquisa G2E-UFSC [Grupo de Educação e Entretenimento - UFSC], para pesquisar e desenvolver produtos e serviços na área educacional e comercial. As áreas de trabalho atual são: gestão da informação aplicada; gestão do design; projeto de ações estratégicas voltadas a inovação; animação; games; e direção de arte.

\section{Eugenio Andres Diaz Merino}

<eugenio.merino@ufsc.br>

Prof. Dr. Coordenador do programa de Pós-Graduação em DesignCoordenador do Curso de Especialização em Gestão de Design Coordenador do Núcleo de Gestão de Design e Laboratório de Design e Usabilidade e Vice-coordenador da área de Ergonomia pelo Programa de Pós-graduação em Engenharia de Produção.

Artigo recebido em 13 abr. 2014, aprovado em 03 jul. 2014. 